\title{
REVITALIZACIÓN DE CENTROS URBANOS DESDE LA PERSPECTIVA DEL PROGRAMA MAIN STREET EN BARRIOS ALTOS ${ }^{[\star]}$
}

\author{
REVITALIZATION OF URBAN CENTERS FROM THE PERSPECTIVE OF THE MAIN STREET \\ PROGRAM IN BARRIOS ALTOS
}

\author{
AARON URDANIGUE CONTRERAS $S^{[\star]}$
}

Fecha de recepción: 03 de abril de 2017

Fecha de aprobación: 12 de julio de 2017

\section{RESUMEN}

El presente documento busca dar a conocer algunos estudios que desarrollan la importancia de los actores sociales como gestores de la conservación del patrimonio arquitectónico, en especial aquellos que se dedican al comercio tradicional. En ese marco los comerciantes locales tradicionales son los actores más interesados en la revitalización de los centros históricos. Muchas instituciones, tanto públicas como privadas, incentivan actualmente políticas de desarrollo para la revitalización de centros urbanos, como es el caso de la Organización de las Naciones Unidas para la Educación, la Ciencia y la Cultura (UNESCO). En el presente trabajo busca exponer la revitalización "desde adentro" de Barrios Altos. Con ese objetivo, se explica la experiencia norteamericana desde el programa llamado Main Street, que desde inicios de los años 80 se viene desarrollando exitosamente en pequeñas y medianas localidades de los Estados Unidos. Este programa se enfoca en la revitalización del área comercial ubicada principalmente alrededor de la calle principal (main street); de ahí el nombre. Desde esta perspectiva, la investigación busca aterrizar este programa en una zona de Barrios Altos, específicamente en el ambiente urbano monumental de Cinco Esquinas, uno de los lugares más representativos donde todavía tiene lugar un comercio local tradicional y existe arquitectura patrimonial a conservar.

\section{PALABRAS CLAVE}

Main Street, revitalización de centros urbanos, comercio local

\section{ABSTRACT}

The following document aims to present a handful of studies that develop the importance of social actors as one of the groups in charge of the preservation of architectural heritage, especially those involved in traditional commerce. Within this framework, traditional local traders are the actors who are most interested in the revitalization of historical centers. Many institutions, both public and private, currently encourage policies for the development of historical centers, such as the United Nations Educational, Scientific and Cultural Organization (UNESCO). This essay aims to show the revitalization "from within" of Barrios Altos. In this sense, it explains the North American experience from the point of view of the Main Street program, which, since the early 1980s, has been developing successfully in small and medium towns in the United States. This program focuses on the revitalization of commercial areas, usually located around the main street of a town; hence the name. From this perspective, the following investigation seeks to land this program in an area of Barrios Altos, specifically in the monumental urban environment of Cinco Esquinas, one of the most representative spaces, where traditional local commerce is still present and there is patrimonial architecture to be preserved.

\section{KEYWORDS}

Main Street, revitalization of urban centers, local commerce

${ }^{*}$ ) El presente artículo forma parte del plan de tesis aprobado Comercio Local Tradicional en los Barrios Altos. Análisis Estratégico desde la Perspectiva del Main Street en Cinco Esquinas, elaborado bajo la dirección del MSc. Arq. José Hayakawa Casas, iniciado en el 2016 y elaborado para la obtención del grado académico de magíster en Conservación y Gestión del Patrimonio Edificado en la Unidad del Posgrado de la Facultad de Arquitectura, Urbanismo y Artes de la Universidad Nacional de Ingeniería (FAUA-UNI).

$\left.{ }^{(* *}\right)$ Arquitecto por la Universidad Ricardo Palma. Egresado de la maestría en Conservación y Gestión del Patrimonio Edificado de la UNI. Ha dictado conferencias sobre temas relacionados a intervenciones en patrimonio arquitectónico a nivel nacional e internacional. Participó como investigador en estudios conjuntos con la Universitá Sapienza di Roma y la FAUA-UNI. Actualmente se desempeña como docente universitario en distintas casas de estudio, y como especialista en diseño y gestión de proyectos de oficinas y locales comerciales. Contacto: aaron.urdanigue@gmail.com 


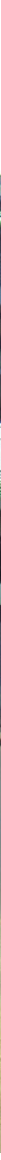

El éxito de la revitalización de un centro histórico radica en la correcta sinergia, participación y coordinación de los actores sociales ${ }^{2}$, como es el caso del comercio local tradicional, el compromiso de los sectores público y privado, y la movilización de un gran número de voluntarios dispuestos a realizar actividades Asimismo, es indispensable para tener éxito que el programa local cuente con la participación e involucración de todos los integrantes de la comunidad, tanto grupos sociales como individuos (National Trust for Historic Preservation [NTHP], 1995).

El poblador local no había sido tomado en cuenta en anteriores enfoques de revitalización del CHL: las decisiones provenían verticalmente de las autoridades públicas, sin el involucramiento del vecino. Por ende, solo era considerado un destinatario, un personaje incapaz de involucrarse en las soluciones que le conciernen a su entorno inmediato. El cambio de enfoque orientado al ciudadano hace protagonista al poblador oriundo y lo empodera en el desarrollo directo de su comunidad.

Bajo esta perspectiva, el poblador se convierte en un actor local perfilado en la actividad comercial de escala local, guiado por una administración pública y privada, para que sea el protagonista del desarrollo que revitalice el centro histórico. En ese sentido, Caraballo (citado en Hayakawa, 2010) enfatiza la necesidad impostergable de priorizar la acción de recuperación de los centros históricos al fomentar la lectura del propio centro desde dentro, rescatando las memorias y construyendo las nuevas visiones de sus habitantes (Figuras 1, 2 y 3 ).

Por otro lado, el enfoque de aislamiento que se ha aplicado al $\mathrm{CHL}$, dentro de otras malas iniciativas de restauración, como la restauración superficial de sus fachadas, ha
Figura 2. Obra pública del tren eléctrico, a escala inapropiada, en el entorno urbano-monumental del Centro Histórico de Lima. Archivo fotográfico personal A. Urdanigue, 2011.

2. Actores sociales se refiere a individuos o grupos de personas, y las formas en que estos interactúan y se relacionan con la ciudad. 
devenir Vol. 4, N8, JULIO - DICIEMBRE 2017, pp. 33-48 - Estudios I ISSN 2312-7562 I E-ISSN 2616-4949

UNIVERSIDAD NACIONAL DE INGENIERÍA, LIMA

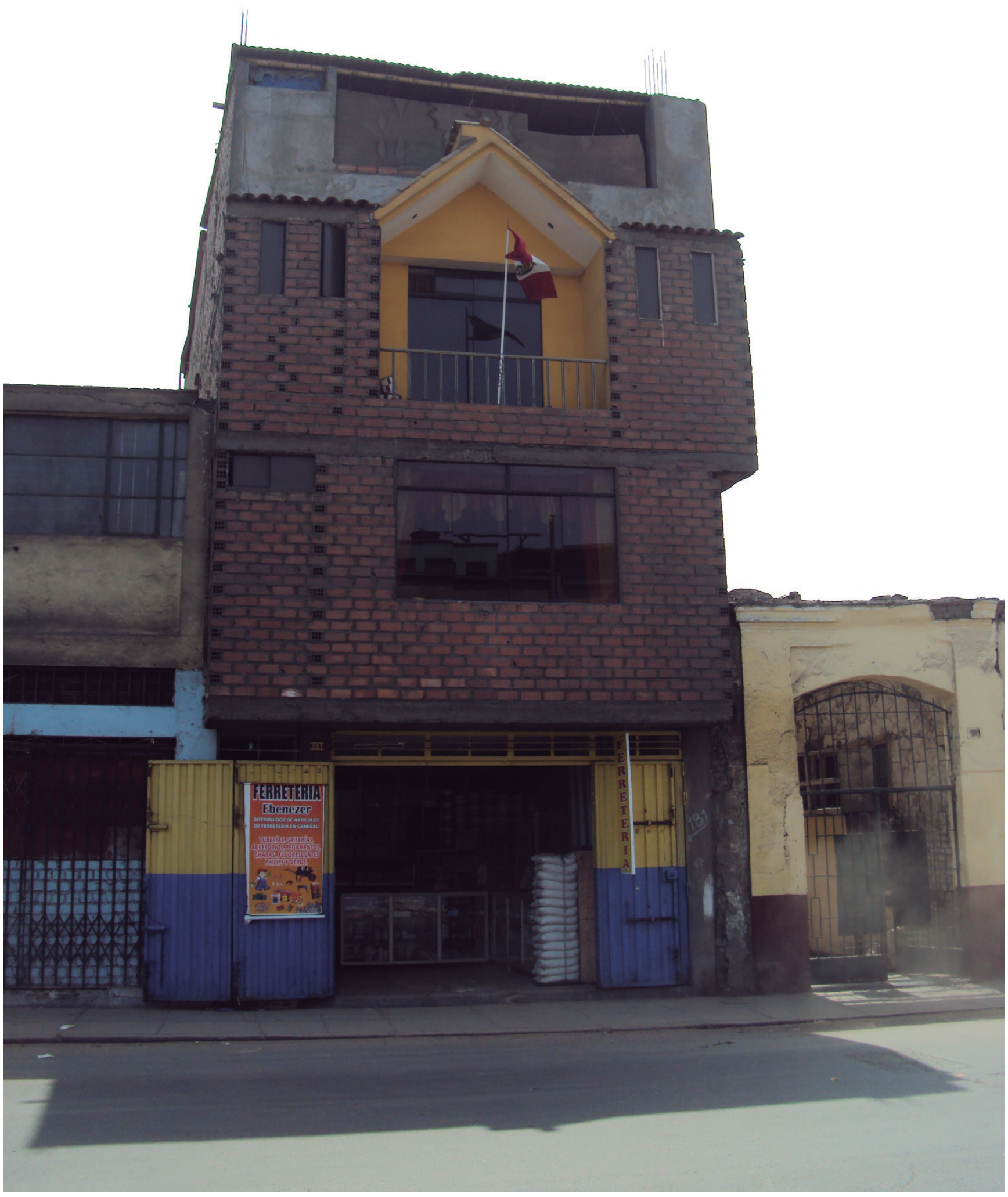

Figura 3. Intervenciones arquitectónicas de mala calidad en los Barrios Altos. Archivo fotográfico personal A. Urdanigue, 2011. 
generado que este sea percibido como una ciudad-museo. Resulta contraproducente evitar que las dinámicas sociales, culturales y económicas que se desarrollan en el resto de la ciudad no se generen en el $\mathrm{CHL}$, porque a fin de cuentas este centro urbano es parte de una gran ciudad, cuyo éxito radica en la integración y armonía de todos sus sectores. Excluir a esta zona de la ciudad y no integrarla al resto produce un aislamiento peligroso con consecuencias aún peores que las actuales.

Asimismo, desde el año 2008 se está incrementando el valor de los terrenos del CHL, alza impulsada principalmente por la actividad comercial. Esto ha hecho que el valor del terreno alcance los U\$ 917 por $\mathrm{m}^{2}$ en los predios que están circunscritos en el damero de Pizarro, costo mucho más elevado que en otras zonas de la ciudad, como Lima Norte, Este, Sur y Callao (Lozada, 2014). La actual dinámica comercial continúa elevando el valor del terreno, lo cual podría ser aprovechado para generar inversión inmobiliaria en lugares con problemas sociales y económicos, como el caso de Barrios Altos, zona caracterizada por la precariedad de las viviendas y los altos índices de inseguridad, entre sus principales problemas. No se trata de considerar la actividad comercial un elemento negativo, sino más bien reconocer que es un factor importante en la revitalización del centro histórico, cuya correcta planificación, con trabajo coordinado, puede significar el éxito de una sostenible recuperación del entorno urbano monumental. Delgadillo (2008) menciona lo siguiente: "En este sentido, se promueve que la vivienda aloje usos mixtos equilibrados (vivienda, comercio, talleres), para generar actividades productivas y cruzar financiamiento y subsidios, particularmente en beneficio de la población residente de bajos ingresos" (p. 90). Esta diversidad de planteamientos y propuestas que se generan para desarrollar el $\mathrm{CHL}$ deben tener un carácter dual, para poder abarcar dos aspectos tan importantes como el cultural y natural como dinamizadores del desarrollo, y así conseguir el doble efecto de preservar la cultura y desencadenar dinámicas de desarrollo urbano en las comunidades que le dan sentido al patrimonio. Sin estas propuestas, muy probablemente, la batalla seguirá estando perdida (Ariza \& Hayakawa, 2015).

\section{Políticas de inclusión social}

Los gobiernos latinoamericanos, especialmente el Perú, se encuentran desarrollando políticas de inclusión social para la mejora en la calidad de vida de los sectores sociales económicamente vulnerables. Esta corriente está siendo impulsada principalmente por organismos internacionales. Al respecto, el economista Gonzales comenta que la inclusión "se ha colocado en la palestra a partir del pensamiento de Amartya Sen retomado por el Banco Mundial y el Banco Interamericano de Desarrollo (BID). Ellos redefinieron sus políticas sociales en función a la inclusión" (citado en Zubieta, 2014).

Los organismos internacionales de cooperación y desarrollo juegan un rol importante en la promoción de políticas sociales, y en esa línea el gobierno peruano creó en 2011 el Ministerio de Desarrollo e Inclusión Social (MIDIS), cuyo principal objetivo es

Mejorar la calidad de vida de la población en situación de vulnerabilidad y pobreza, promover el ejercicio de sus derechos, el acceso a oportunidades y al desarrollo de sus propias capacidades. El MIDIS coordina y articula con las diversas entidades del sector público, el sector privado y la sociedad civil, fomentando que los programas sociales consigan sus metas lográndolo a través de una constante evaluación, potenciación, capacitación y trabajo coordinado entre sus gestores. (MIDIS, 2011, párr. 1)

Es importante destacar que el principal objetivo del MIDIS, mejorar la calidad de vida de poblaciones vulnerables -promover sus derechos, acceso y desarrollo de capacidades y oportunidades, así como gestar programas sociales con sectores públicos, privados y sociedad civil-, es un objetivo compartido e impulsado por la UNESCO para el desarrollo de centros históricos. 
UNESCO (2011) presenta una norma enfatizada como recomendación sobre el paisaje urbano histórico, que su vez incluye un glosario de definiciones en el cual, en cuanto al desarrollo, se plantea lo siguiente:

Muchos procesos económicos ofrecen medios para aliviar la pobreza urbana y promover el desarrollo social y humano. El hecho de acceder más fácilmente a innovaciones como las tecnologías de la información o métodos de planificación, concepción y edificación sostenibles puede traer consigo mejoras de las zonas urbanas, y por ende una mejor calidad de vida. (UNESCO, 2011, párr. 30)

Así mismo, es importante la acotación que hace la UNESCO (2011) sobre el aspecto de nuevos servicios, y su gestión en tantos impulsores del desarrollo económico y a su vez promotores de la conservación de centros históricos. Nuevas funciones como los servicios o el turismo, si se aplica correctamente la noción de paisaje urbano histórico a su gestión, pueden imprimir un notable impulso económico, y contribuir así al bienestar de las comunidades y a la conservación de los conjuntos urbanos históricos y su patrimonio cultural sin menoscabo de su diversidad socioeconómica y de su función residencial. Además, señala que de no seguir este modelo de desarrollo para centros históricos, su sostenibilidad en el largo plazo sería inviable y los resultados serían negativos para las futuras generaciones: "Dejar escapar esas oportunidades tiene por resultado ciudades insostenibles e inviables, y aprovecharlas de forma incorrecta o insuficiente desemboca en la destrucción de elementos valiosos del patrimonio y en pérdidas irreparables para las generaciones futuras" (UNESCO, 2011). Según Jeff Soule ${ }^{3}$ plantea en Tres componentes para lograr Centros Históricos Sostenibles, artículo publicado por el BID, el primer componente de desarrollo para un centro histórico "la capacidad del patrimonio cultural para fomentar el desarrollo económico inclusivo" (2015, párr. 9). El valor que tienen los centros históricos es inseparable de su característica de patrimonio cultural, condición que promueve la revitalización económica de centros históricos, pues fomenta la creación de nuevos puestos de trabajo para la población local.

Como segundo componente, se plantea al "patrimonio cultural como el facilitador de la cohesión social, la inclusión y la equidad" (BID, 2015). Al valorar la identidad de los centros históricos, los ciudadanos adquieren un sentimiento de pertenencia, haciendo suyo el patrimonio cultural de su entorno.

Como tercer componente se acota que "los barrios y centros históricos pueden mejorar la habitabilidad, así como la sostenibilidad de las zonas urbanas" (BID, 2015). Al ser los centros históricos lugares donde los servicios y la movilidad se concentran en espacios de poca extensión, resulta coherente promover en ellos la peatonalización y/o el uso de la bicicleta, opciones que brindan beneficios para la salud, son amigables con el medioambiente y promueven un mejor manejo de los recursos naturales. Estas prácticas también promueven la reutilización de antiguas construcciones para usos contemporáneos, lo cual contribuye a hacer los centros históricos sustentables.

Resulta pertinente destacar una investigación llevada a cabo por Lozada (2014), donde demuestra que residir en nuevas viviendas multifamiliares en el CHL es más rentable económicamente para el ciudadano de escasos recursos que habitar lugares alejados del CHL, como el distrito de Carabayllo, donde se están gestando las principales obras de construcción de viviendas y venta de terrenos para los niveles socioeconómicos $C$, D y E. Además, hace énfasis especial sobre la participación del Estado en las políticas de recuperación de centros históricos, indicando que este podría asumir los principales costos de transacción para incentivar al sector privado a invertir en proyectos dirigidos a las familias más vulnerables, promoviendo así la integración social, y brindando oportunidades laborales y acceso a servicios básicos (Lozada, 2014, p. 87).

3. Jeff Soule, nacido en Estados Unidos, experto en planificación y desarrollo urbano sostenible. 


\section{FIn \\ BAJA PUNTACIÓN EN EL CARACTER \\ ALTA PUNTACIÓN EN EL CARACTER}

\section{${ }^{\circ}$ EDIFICIOS ANTIGUOS \\ ${ }^{\circ}$ EDIFICIOS PEQUEÑOS \\ - MAYOR DIVERSIDAD DE EDAD}

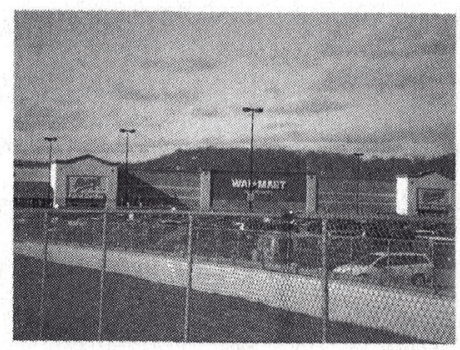

Sobre procesos de revitalización en sitios con patrimonio cultural, en Lima se cuenta con la experiencia local de la huaca Pucllana, cuyo desarrollo y sostenibilidad principalmente se sostiene principalmente en céntrica ubicación con respecto a la Lima moderna. Su revaloración y puesta en valor tuvo un efecto revitalizante, que logró una perfecta integración de la huaca con su entorno inmediato. Al respecto, Álvarez-Calderón (2014) indica que un sitio arqueológico puesto en valor tendría el mismo efecto que un parque $u$ otro espacio abierto revitalizado ubicado en un área urbana. Estos espacios, sean privados o públicos, tienden a incrementar el valor de las propiedades (Municipalidad Metropolitana de Lima [MML], 2014).

\section{Marco teórico}

La presente investigación se basa en la teoría del Main Street y en el estudio El valor del Patrimonio Cultural.

En cuanto a la estrategia del Main Street para la revitalización de los centros históricos, esta se inició como una iniciativa comunitaria para salvar el patrimonio inmueble histórico a través de la reactivación comercial de las ciudades y pueblos a lo largo de los Estados Unidos. A partir de la década de 1950, dichas ciudades han sufrido cambios significativos en sus dinámicas comerciales, debido a la migración de los locales comerciales que se ubicaban originalmente en el centro de las ciudades o pueblos hacia zonas periféricas de estas, para situarse en los nuevos malls. Dicho desplazamiento propició una baja drástica en la afluencia de público a los locales comerciales tradicionales de la ciudad ubicados en el centro, que como consecuencia empezaron a decaer. El público dejó de recorrer dichas calles, como si en ellas no tuvieran lugar las dinámicas sociales, comerciales y culturales de antaño. Ello ocasionó que el entorno urbano tradicional y sus edificios patrimoniales de valor histórico sean olvidados y empiecen a deteriorarse.

En un intento por rescatar el patrimonio histórico inmueble y el distrito histórico comercial, los propietarios de los locales comerciales empezaron a imitar a los malls en sus fachadas, lo cual propició intervenciones arquitectónicas no compatibles con la arquitectura existente del lugar. Entre los cambios más notorios estuvieron la coloca-
Figura 4. La diferencia entre puntajes altos y bajos del carácter del barrio según la teoría del Main Street. En Revitalizando los centros urbanos ( $p$. 48), por el National Trust for Historic Preservation, 2016, Washington, D.C.: Autor. 
ción de vidrios tipo espejo y la modificación de las proporciones arquitectónicas en las fachadas, y la instalación de luces de neón en los anuncios publicitarios, cambios en gran medida irreversibles, que distorsionaron su imagen, haciéndola escenográfica e incompatible con lo que debería representar el centro.

La revitalización del centro histórico o distrito comercial es importante porque permite mantener una economía fuerte, y refuerza la consideración del patrimonio como orgullo cívico de la comunidad. Las revitalizaciones, a largo plazo, fomentan la permanencia de negocios que usan los servicios públicos, promueven mayores ingresos económicos a la ciudad, y permiten conservar y crear nuevos puestos de trabajo, recaudar más impuestos, mejorar la calidad y aumentar la cantidad de bienes de servicio, así como promover una mejor calidad de vida (NHTP, 1995). Adicionalmente, los barrios que tienen un carácter patrimonial presentan una mayor diversidad de personas de distintas generaciones en comparación a otras zonas de la ciudad (Meeks \& Murphy, 2016). (Figura 4)

Según el NTHP (1995), el enfoque de Main Street implica cuatro aspectos: diseño, organización, promoción y reestructuración económica.

El diseño abarca el mejoramiento de la arquitectura del centro, distrito o calle comercial. Además, incluye el mejoramiento del entorno urbano, lo cual implica intervenciones en pistas, veredas y todo lo que compete a su imagen urbana.

La organización involucra la articulación de todos los grupos económicos y civiles que tienen interés en la mejora del centro y su desarrollo económico: banqueros, dueños de propiedades, administradores del distrito, comerciantes, residentes del centro, profesionales, representantes de la Cámara de Comercio, industrias locales, grupos cívicos, sociedades históricas, escuelas, consumidores, agentes de bienes raíces y medios locales de comunicación.

La promoción está orientada a exaltar los principales valores y características del centro histórico ante los actores externos, para crear una imagen positiva del lugar promocionando, y desarrollar actividades y eventos.

La reestructuración económica refuerza la economía del lugar, al mismo tiempo que la transforma, produciendo varias oportunidades de comercio y negocio. Esta reactivación económica dinamiza el área generando competitividad entre los comerciantes locales, lo cual favorece al consumidor local. Además, permite reutilizar los edificios o locales vacíos y hacerlos productivos (NTHP, 1995).

El éxito del plan del Main Street radica en la perfecta coordinación y armonía de sus cuatro enfoques, lo cual lleva a la creación de una nueva estrategia para una correcta administración. Esto conlleva a un mejoramiento en las economías de los lugares intervenidos y promueve la conservación de los edificios de carácter patrimonial histórico (Ver Figura 5).

El proyecto Main Street se organiza en torno a ocho valores. En primer lugar, cuenta con un enfoque completo para la revitalización del centro de una ciudad o pueblo. El enfoque de este plan es amplio, y abarca todas las áreas donde se necesita una intervención urgente, a diferencia de otros planes de revalorización, que se basan en intervenciones puntuales como la renovación de fachadas. Está comprobado que tener una visión holística del problema repercute en un cambio más positivo que su consideración fragmentada.

Además, el enfoque Main Street se fundamenta en la calidad de la arquitectura que se encuentra en los centros históricos, manifestación de sus características innatas, que los hacen ser reconocidos como únicos y los diferencian de los centros comerciales. Ello implica reconocer el valor de las construcciones y convertirlas en fuente orgullo. Asimismo, todo proyecto a realizarse en un centro histórico debe responder a dichos estándares de calidad arquitectónica. 

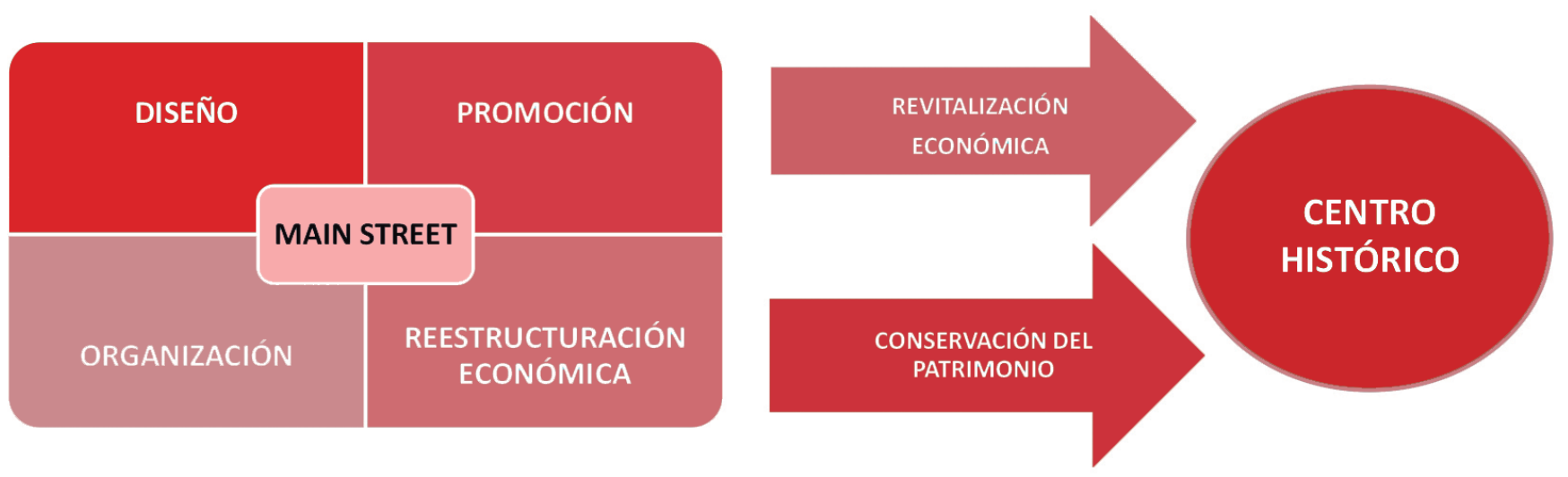

Para llevar a cabo una revitalización, es necesaria la asociación entre el sector público y privado. La experiencia de estos dos sectores en la promoción de planes de desarrollo locales es importantísima para poder lograr un trabajo coordinado, pues de la articulación correcta de ambos dependerá el éxito del proyecto.

Por otro lado, Main Street promueve un cambio de actitudes. Debido al continuo deterioro de los centros históricos por el abandono de sus dinámicas comerciales, muchos actores locales dudan de la revitalización de estos lugares; sin embargo, al percibir los primeros cambios positivos, la gente empieza a cambiar de actitud: entonces se inicia el éxito del programa de revitalización.

El foco del proyecto Main Street son las propiedades inmuebles existentes, los recursos que tiene cada comunidad como parte del legado arquitectónico que los distingue de otras comunidades.

Asimismo, se trata de un programa de esfuerzo propio. Ello quiere decir que, si bien el programa recibe algunas subvenciones para hacer operativas algunas funciones administrativas, es en el esfuerzo de los actores locales donde radica el éxito del programa.

Por otro lado, el proyecto Main Street se realiza por etapas. Así como el deterioro de una ciudad no sucede repentina, sino paulatinamente, los programas de revitalización deben seguir una línea de gradual de cambios para que se consoliden en el futuro.

Finalmente, el programa está orientado hacia la implementación, por lo que es importante identificar los asuntos de mayor importancia para que se priorice trabajar en ellos (NTHP, 1995, pp. 4-5).

Por otro lado, como parte del análisis teórico esta investigación se basa en El Valor del Patrimonio Cultural (Ranaboldo \& Schejtman, 2009). Este texto propone que cualificar y/o valorar un territorio con patrimonio cultural conlleva el análisis de numerosas variables, desde el aspecto material hasta el inmaterial. Este valor es asignado por un grupo de personas, sociedades, naciones, e instituciones públicas y privadas que reconocen en esos valores características e identidades únicas que ameritan su preservación y puesta en valor, en tanto testimonio de un pasado sobresaliente para el conocimiento de futuras generaciones. Las nuevas políticas de gestión valoran modelos de desarrollo para las poblaciones que residen en ambientes monumentales, políticas que han impulsado numerosas estrategias que integran al actor local como protagonista del devenir de su entorno inmediato.
Figura 5. Esquema del programa Main Street. Elaboración propia, 2017. 
Cabe destacar que este concepto del valor del patrimonio cultural no solo es operativo en el ámbito rural, sino que también puede aplicarse en el ámbito urbano, pues existen valores intrínsecos que caracterizan a ambos entornos y dan forma a su identidad. Asimismo, es importante tener en cuenta que las experiencias provenientes del ámbito rural aconsejan que es importante la aprobación y aceptación de los pueblos para desarrollar proyectos en sus lugares de origen.

Además, el territorio debe abordarse desde la identidad y con un proyecto de desarrollo concertado socialmente, que no debe ser impuesto, sino que debe construirse de forma participativa entre la comunidad (Ranaboldo \& Schejtman, 2009). Es evidente que el desarrollo y la revitalización económica no dependen únicamente de la correcta relación entre los actores interesados, sino que deben integrar y resaltar los valores que los han unido.

Por lo tanto, estos principios también son válidos para poblaciones de entornos urbanos fundacionales, donde la participación comunitaria y el reconocimiento de su identidad redundan en la valoración del entorno urbano patrimonial.

Dicha identidad es susceptible de ser valorada por varios actores locales, en especial por uno externo, el turismo, que busca en tiempo de globalización sociedades y/o culturas que mantengan valores únicos de identidad. Esta renovada valoración de las culturas se caracteriza por integrar actores locales con capacidades e intereses de distinto nivel. El éxito de la revitalización de un territorio con valor patrimonial depende del interés, compromiso y esfuerzo de los actores locales; y la retribución será para su propio beneficio y el del entorno patrimonial. Así, se deben promover liderazgos que incentiven a las comunidades a tomar conciencia del valor de su patrimonio, de forma que de esta emerja un modelo de desarrollo sostenible para la colectividad.

La revaloración cultural vinculada al desarrollo territorial se expresa en procesos diversos, heterogéneos, que involucran actores diferentes que detentan intereses diversos y a veces divergentes. El concepto de desarrollo territorial requiere la confluencia de todos los actores en el consenso de intereses que beneficien a la colectividad. En ese sentido una buena organización local posibilitaría la aplicación y operatividad de programas de desarrollo en los ámbitos anteriormente señalados. Asimismo, la inversión en la valorización de la identidad cultural puede constituir una estrategia efectiva de desarrollo sostenible e incluyente de dichos territorios (Ranaboldo \& Schejtman, 2009).

Sobre este tema, Frey \& Pommerehne (1989) manifiestan varios tipos de valores. La opción de valorar (imaginariamente) está en la satisfacción de alguien que tiene la oportunidad de experimentar, usar y disfrutar de un objeto particular patrimonial. El valor de su existencia equivale al valor contenido en el disfrute de la mera existencia de un bien patrimonial, pero no del disfrute de su presencia o de su uso actual. Por otro lado, el valor del legado es el valor que las futuras generaciones pueden obtener de un bien patrimonial, y el valor de prestigio es, como su nombre lo indica, el prestigio que una comunidad o persona se adjudica por tener cierto patrimonio. Por último, el valor de la educación abarca todos los beneficios que el patrimonio genera en términos de educación ${ }^{4}$ (Getty Conservation Institute, 1998).

\footnotetext{
4. Texto original: "Frey and Pommerehne (1989) distinguish various values that individuals may attach to heritage goods. Option value is the (imaginary) satisfaction someone experiences of having the opportunity to use or enjoy a particular piece of heritage. Existence value amounts to the value contained in the enjoyment of the mere existence of a heritage good - not of enjoyment of its presence or actual use of it. The bequest value is the value that future generations derive from a heritage good, and the prestige value is as its says: the prestige that a community or person derives from having a particular heritage good. Finally, the education value captures all benefits that heritage generates in terms of education." (Getty Conservation Institute, 1998, p. 31)
} 
Los parámetros o indicadores que permiten medir o discriminar qué puede ser catalogado como patrimonio y qué no son numerosos, y están ligados a la idiosincrasia de la sociedad que califica. En relación a esto, Hayakawa (2010) menciona lo siguiente:

La manera de evaluar los valores patrimoniales resulta una tarea bastan difícil, indudablemente resultante de varias de sus características esenciales: diversa naturaleza de los valores patrimoniales, grupos de los cuales se superponen o compiten, lo valores cambian cada tiempo y son fuertemente delineados por factores contextuales. (p. 39)

Ante esta amplitud de criterios para valorar el patrimonio, el Getty Conservation Institute (2002) considera pautas que sirven como parámetros para hacer más sencilla la catalogación del valor patrimonial:

- La conservación del patrimonio es la mejor manera de entender cómo una actividad sociocultural, no simplemente una práctica técnica, abarca muchas actividades precedentes y posteriores a cualquier acto material de intervención.

- Es importante tener en cuenta el contexto del proyecto de conservación patrimonial -social, cultural, económica, geográfica, administrativa- tan seria y profundamente como el objeto/sitio en sí es considerado.

- El estudio de los valores es una manera útil de entender los contextos y aspectos socioculturales de la conservación del patrimonio.

- Los valores del patrimonio son, por naturaleza, variados, y están a menudo en conflicto.

- Los tradicionales modos de evaluar el "significado" del valor se basan en gran medida en su aporte histórico, artístico-histórico y los conocimientos arqueológicos obtenidas por profesionales, y se aplican básicamente a través de métodos unidisciplinarios.

- La consideración de los valores económicos, un condicionante muy fuerte de la conservación del patrimonio, está fuera del ámbito tradicional de los profesionales de la conservación, y su integración con los valores culturales representa un particular reto.

- No hay disciplina o método que proporcione una completa o suficiente evaluación de los valores patrimoniales; por lo tanto, la combinación de los métodos de una variedad de disciplinas debería estar incluida en cualquier evaluación integral de los valores patrimoniales.

- Para la gestión de la conservación y el planeamiento se debe emplear una estrategia de inclusión, que convoque diferentes disciplinas, y brinde los puntos de vista de los "involucrados" $y$ "no involucrados" en el proceso de planificación.

- Una evaluación más global del valor del patrimonio y la integración de diferentes valores conducirá a una mejor planificación de la conservación, más sostenible y administrable.

- La prueba más efectiva de una conservación planificada es su capacidad de respuesta a las necesidades de los interesados, las comunidades y la sociedad contemporánea. ${ }^{5}$ (Getty Conservation Institute, 2002, pp. 5-6).

- El Programa de las Naciones Unidas para el Desarrollo (PNUD, 2016) indica la importancia del comercio local en el desarrollo económico, que se debe a la capacidad de generar puestos de trabajo, parte fundamental de la reducción de la pobreza y la promoción de la inclusión social. Principalmente estos problemas, entre otros, son los que se presentan en la zona de los Barrios Altos, y la atención de estos por parte de los

5. Traducción realizada por el autor. 
devenir Vol. 4, N8, JULIO- DICIEMBRE 2017, PP. 33-48 - Estudios I ISSN 2312-7562 I E-ISSN 2616-4949

UNIVERSIDAD NACIONAL DE INGENIERÍA, LIMA

Tabla 1. Cuadro comparativo Main Street - Barrios Altos

Programa Main Street

El enfoque del Proyecto Main Street es un enfoque completo para la revitalización del centro de una ciudad o pueblo.

El enfoque de Main Street se fundamenta en la calidad.

Es necesaria la asociación con el sector público y privado para lograr una revitalización.

El proyecto Main Street promueve un cambio de actitudes.

El proyecto Main Street se concentra en las propiedades inmuebles existentes.

\begin{tabular}{ll}
\hline $\begin{array}{l}\text { El programa Main Street es un progra- } \\
\text { ma de esfuerzo propio. }\end{array}$ & $\begin{array}{l}\text { Existe conciencia en los comerciantes de la zona de } \\
\text { que solo con el esfuerzo y compromiso de ellos mismos } \\
\text { podrán sacar adelante programas de desarrollo en } \\
\text { Barrios Altos. }\end{array}$ \\
\hline $\begin{array}{l}\text { El proyecto Main Street se realiza por } \\
\text { etapas. }\end{array}$ & $\begin{array}{l}\text { Las dimensiones del programa exigen su implementa- } \\
\text { ción por etapas. Así, que su aplicación podría desarro- } \\
\text { llarse en pequeñas zonas icónicas que puedan después } \\
\text { impulsar el desarrollo en otros lugares. Uno de estos } \\
\text { lugares sería Cinco Esquinas, en Barrios Altos. }\end{array}$ \\
\hline $\begin{array}{l}\text { El programa Main Street está orientado } \\
\text { hacia la implementación. }\end{array}$ & $\begin{array}{l}\text { Los actores locales (comerciantes locales), como } \\
\text { protagonistas del programa Main Street, son los que } \\
\text { priorizarían sobre la base de su conocimiento del lugar, } \\
\text { los aspectos más urgentes a resolver para revitalizar la } \\
\text { zona. }\end{array}$ \\
\hline
\end{tabular}

Elaboración propia, 2017.
Los problemas actuales en Barrios Altos no se ciñen exclusivamente a lo arquitectónico, sino a múltiples factores de deterioro, como el factor económico y social.

Aún existe arquitectura patrimonial de calidad que hace única a esta zona del CHL.

Existe una incipiente organización del sector comercial en la zona que podría mejorar para poder asociarse con el sector público y así desarrollar programas de revitalización.

El inicio de este programa provocaría en el poblador, a partir de la revalorización, un cambio de actitud respecto de su entorno.

Existe patrimonio inmueble que puede ser rescatado, mediante un desarrollo tangible, y no en base a mitos o leyendas.

Existe conciencia en los comerciantes de la zona de que solo con el esfuerzo y compromiso de ellos mismos podrán sacar adelante programas de desarrollo en Barrios Altos.

as dimensiones del programa exigen su implementampulsar el desarrollo en otros lugares. Uno de estos lugares sería Cinco Esquinas, en Barrios Altos.

ales), com priorizarían sobre la base de su conocimiento del lugar, zona. 
actores locales, las autoridades y la comunidad, los involucra de manera directa; de no ser así, cualquier tipo de emprendimiento de programas o planes de revitalización de la zona no será sostenible en el tiempo.

- El comercio puede ser una fuente de inclusión: actualmente los actores locales, como los comerciantes, son piezas fundamentales en el desarrollo social y económico de las ciudades $y$, por ende, repercuten en la conservación del patrimonio arquitectónico. Por lo tanto, no es posible revitalizar un centro histórico sin atender el problema de la pobreza y la falta de trabajo en los centros históricos venidos a menos, como en Barrios Altos. Además, dicha reducción de la pobreza está dentro de los Objetivos de Desarrollo del Milenio (ODM), impulsados por las Naciones Unidas.

- El desarrollo debe ser local y participativo. Los ODM solo pueden lograrse a través de acciones a nivel local: en pueblos y ciudades, provincias y regiones. Los actores locales, los líderes comunitarios, los funcionarios de los gobiernos locales, los activistas de la sociedad civil, los agricultores y los empresarios saben qué funciona y no funciona dentro de sus comunidades, y deben contar con la voz y el apoyo necesario para construir su camino hacia una mejor calidad de vida. Al mismo tiempo, el desarrollo local debe estar integrado en el proceso de desarrollo nacional.

- Debe involucrarse al sector privado. El logro de los ODM depende de un crecimiento económico dinámico, impulsado por empresas privadas que crean puestos de trabajo, y proporcionan bienes y servicios para la población pobre, además de generar ingresos fiscales que permitan financiar la infraestructura social y económica. Por lo tanto, el sector privado - desde grandes empresas multinacionales hasta pequeñas empresas y cooperativas de mercados locales- también tiene un papel esencial que desempeñar en el logro de los principales objetivos del PNUD (2016), específicamente en asuntos relacionados al medio ambiente, energía y prestación de servicios ambientales, prevención de crisis, igualdad de género y gobernabilidad democrática.

A partir de conocer la realidad problemática de Barrios Altos y la revisión teórica sistematizada del modelo, es que se propone la aplicación del programa Main Street en Cinco Esquinas sobre la base de los ocho enfoques del programa, los cuales tienen relación con el área de estudio (ver Tabla 1).

El CHL, en especial la zona de Barrios Altos, se ha visto perjudicado en su dinámica original por muchos factores externos, lo que amerita una necesaria intervención en salvaguarda del patrimonio edificado.

Para realizar esta intervención se podría crear mejores accesos al área, promover mejoras públicas y realizar mantenimiento de los edificios (diseño). Además, debe prestarse atención a aquellos negocios que son más apropiados para el área, de modo que se promuevan los bienes y servicios que el centro ofrece (promoción). Es necesario fortalecer los negocios existentes, que a su vez atraerán a otros nuevos al sector (reestructuración económica). Finalmente, es la convocatoria al trabajo y esfuerzo comunitario lo que hará posible los cambios (organización).

\section{Conclusiones}

La importancia de un enfoque holístico radica en valorar un inmueble no solo por su calidad única, su valor de compra, o su valoración por demanda y utilidad; es la conjunción de estos aspectos lo que brinda una imagen completa del valor del patrimonio, ya que este está expuesto por condicionantes de otros actores, como fuerzas políticas, fuerzas sociales y actores económicos. Y su valor no es fijo, sino que fluctúa por acción del mercado. 
La imagen que se produce mediante el enfoque completo de Main Street reafirma el carácter histórico único de zonas como Barrios Altos, que conservando lo poco que aún queda de su arquitectura de los siglos XVIII y XIX, rescatando usos y actividades inherentes al comercio histórico tradicional que caracterizaron esta zona (restaurantes, bares, sastrerías), devolviéndole dinámicas y costumbres sociales que expresan su identidad y lo hace único, pueden ser revitalizadas.

Se trata de una identidad tan potente como la que otorga ser el corazón del criollismo y el universo costumbrista costeño limeño que ello conlleva. Un criollismo que no solo se ciñe a la música, sino que también abarca maneras del "buen vivir" que se ven reflejadas en un entorno arquitectónico patrimonial, como es el caso de Cinco Esquinas, que acompaña a esta puesta en escena. Al desaparecer produciría la pérdida de la memoria tangible de las costumbres, tan importante en la formación de la identidad de una sociedad como la limeña que, al perderse, condenaría al criollismo a desaparecer.

La revitalización del comercio histórico tradicional de entornos patrimoniales redundaría en el aumento del valor de compras en toda el área comercial de Barrios Altos, especialmente en las calles principales, como Junín, Miroquesada y Áncash. Un punto de inicio de esta transformación sería la zona del entorno monumental de Cinco Esquinas, corazón de todo Barrios Altos por su arquitectura, usos, tradiciones y costumbres.

Este cambio provocaría el deseo de la gente de ir a comprar e invertir en esta zona del CHL. La utilidad y conveniencia de contar con fácil acceso al área, seguridad ciudadana, puesta en valor de los edificios, y mejoras de los espacios y el transporte público son aspectos muy potentes que facilitarían la preservación de una identidad que hace a la zona única y la diferencia de cualquier otro sitio comercial, un valor agregado: cultura con identidad.

La aplicación del programa Main Street ayudaría a que el CHL recupere su esencia única y su importancia mediante la revitalización económica y la conservación de su arquitectura (NTHP, 1995). El éxito del programa radica en la participación comprometida y activa de los actores locales, que en este caso serían los comerciantes, los principales interesados en que la situación de lugar cambie, ya sea porque viven, trabajan, tienen propiedades o se sienten identificados con el patrimonio arquitectónico del lugar.

Los comerciantes y los comercios que respetan y valoran el patrimonio arquitectónico son los llamados a iniciar la revitalización de los centros históricos, ganándole terreno al comercio destructor, fuera de escala e indiferente con el entorno monumental, que se viene desarrollando de manera desenfrenada en el CHL. Son estos comercios los que fomentan la práctica desleal y el trabajo esclavizador de jóvenes.

Según el PNUD (2016), es parte de esta revitalización la reestructuración económica de un barrio o ciudad, y los sistemas de financiación son piezas fundamentales en dicha estructura. La capacidad de un país para reducir la pobreza y fomentar el desarrollo depende de distintos factores: la geografía física, las opciones políticas, los recursos, las instituciones y las capacidades a las que tiene acceso. Además, un aspecto fundamental y decisivo es la financiación económica, necesaria para que un país pueda invertir en infraestructuras o programas que apoyen el crecimiento económico y el desarrollo. Aunque lo más importante son los recursos internos, estos son insuficientes para atender la magnitud de las inversiones necesarias. Es por eso que, a menudo, estos deben ser complementados con ayuda exterior y el alivio de la deuda.

Para el PNUD (2016), lograr que el desarrollo social sea inclusivo debería ser uno de los objetivos principales de cualquier programa de revitalización de centros históricos, ya que insertando a la población de menos recursos en los esquemas de desarrollo se lograría un crecimiento sostenible en el tiempo. En la realidad, muchas 
personas quedan excluidas de los avances del desarrollo debido a su género, etnia, edad, orientación sexual, discapacidad o porque viven en la pobreza. Los efectos de esta exclusión son asombrosos; extienden la desigualdad por todo el mundo. El desarrollo puede ser inclusivo y ayudar a reducir la pobreza solo si todos los grupos de personas contribuyen a crear oportunidades, se benefician del desarrollo y participan en la toma de decisiones. Una vía clave a considerar de parte de las naciones para lograr el desarrollo incluyente es la creación de empleo productivo y remunerado. Esto debería ir acompañado por redes sociales de seguridad eficaces y eficientes para proteger a quienes no pueden trabajar o ganan muy poco. Para alcanzar los ODM, muchos países en desarrollo también tendrán que mejorar los servicios públicos mediante la construcción de escuelas y hospitales, y la capacitación de maestros y médicos, así como proporcionar acceso a agua, saneamiento y transporte, lo cual requiere un gasto público. Los gobiernos pueden jugar un papel importante en la estimulación del crecimiento y la reducción de la pobreza.

\section{Referencias}

Ariza, R. \& Hayakawa, J. (2015). Patrimonio y plan urbano en Lima: apuestas y desafíos del diagnóstico y propuesta de patrimonio edificado en el PLAM 2035. Devenir, 2(3), 113-136.

Banco Interamericano de Desarrollo. (2015, 15 de octubre). Centros históricos: por qué revitalizar es una apuesta de futuro. Recuperado el 9 de diciembre de 2015 de http://blogs.iadb.org/ urbeyorbe/2015/10/15/centros-historicos-por-que-revitalizar-es-una-apuesta-de-futuro/

Copaira, M. (2015). Intervenciones en los monumentos históricos del Centro de Lima: un análisis de la metodología aplicada en la campaña Adopte un Balcón. Devenir, 2(3), 63-78.

Delgadillo, V. (2008). Mejoramiento habitacional en las áreas urbanas centrales de América Latina. Del combate de tugurios a la rehabilitación habitacional progresiva. INVI, 23(63), 89-120.

Frey, B. \& Pommerehne, W. (1989). Muses and markets: explorations in the economics of the arts. Oxford: B. Blackwell.

Hayakawa, J. (2010). Gestión del patrimonio cultural y centros históricos latinoamericanos. Tendiendo puentes entre el patrimonio y la ciudad. Lima, Perú: Universidad Nacional de Ingeniería.

Lozada, L. (2014). Vivienda de interés social en el centro histórico de Lima. Análisis económico a partir de un caso de estudio. Wasi, 1(1), 71-90.

Meeks, S. \& Murphy, K. (2016). The past and future city. Washington: Island Press.

Ministerio de Desarrollo e Inclusión Social. (2011). ¿Quiénes somos?. Recuperado el 10 de diciembre de 2015 de http://www.midis.gob.pe/index.php/es/nuestra-institucion/sobre-midis/ quienes-somos

Municipalidad Metropolitana de Lima. (2014). Concurso Juan Günter. Investigaciones históricas sobre Lima. En R. Álvarez-Calderón, La ciudad negociada. Los sitios arqueológicos y la formación de la metrópolis de Lima en el siglo XX (pp. 163-207). Lima, Perú: Autor.

National Trust for Historic Preservation. (1995). Revitalizando los centros urbanos (C. Nieto, Trad.) Washington, D.C.: National Trust for Historic Preservation.

Programa de las Naciones Unidas para el Desarrollo. (2016, 16 de diciembre). Áreas de acción. Recuperado de la página web de PNUD, http://www.undp.org/content/undp/es/home/ ourwork/povertyreduction/focus_areas.html

Ranaboldo, C. \& Schejtman, A. (2009). El valor del patrimonio cultural. Lima, Perú: Instituto de Estudios Peruanos.

Soule, Jeff. (2015, 12 de noviembre). Tres componentes para lograr centros históricos sostenibles [Post en un blog]. Recuperado el 10 de diciembre de 2015 de https://blogs.iadb.org/ciudadessostenibles/2015/11/12/tres-componentes-para-lograr-centros-historicos-sostenibles/

The Getty Conservation Institute. (1998). Economics and heritage conservation. Los Ángeles: Autor.

The Getty Conservation Institute. (2002). Assessing the values of cultural heritage. Los Ángeles: Autor. 
devenir Vol. 4, N8, JULIO - DICIEMBRE 2017, pp. 33-48 - Estudios I ISSN 2312-7562 I E-ISSN 2616-4949

UNIVERSIDAD NACIONAL DE INGENIERÍA, LIMA

UNESCO. (2011, 10 de noviembre). Recomendación sobre el paisaje urbano histórico, con inclusión de un glosario de definiciones. Recuperado el 9 de diciembre de 2015 de http://portal. unesco.org/es/ev.php-URL_ID=48857\&URL_DO=DO_TOPIC\&URL_SECTION=201.html

UNESCO. (2018, 17 de enero). Historic Centre of Lima. Recuperado el 17 de enero de 2018 de http://whc.unesco.org/en/list/500/

Zubieta, R. (2014, 3 de julio). ¿A qué nos referimos cuando hablamos de inclusión social?. Recuperado de la página web del diario El Comercio el 10 de diciembre de 2015, de http:// elcomercio.pe/peru/pais/que-nos-referimos-cuando-hablamos-inclusion-social-noticia-1740497 